\title{
Renal cell carcinoma presenting as nonspecific gastrointestinal symptoms: a case report
} This article was published in the following Dove Press journal:
International Medical Case Reports Journal
Background: Renal cell carcinoma (RCC) arises from the renal epithelium and accounts for more than $90 \%$ of kidney cancers. RCC has a diverse range of clinical manifestations. The classical triad of loin pain, hematuria and abdominal mass is only present in $4 \%-17 \%$ of cases. Here, we demonstrate a unique case of RCC presenting as upper gastrointestinal (GI) symptoms without any specific GI involvement.

Case presentation: A 49-year-old man, presented with ongoing severe heartburn, nausea and vomiting for 5 months. The patient further complained of weight loss over the last 2 months. Routine blood tests were normal except raised C-reactive protein and ALP. Examination revealed a large and tender liver, and he was subsequently referred under the upper GI cancer pathway. Esophagogastroduodenoscopy showed hiatus hernia and gastritis. CT scan revealed an 11 and 9 $\mathrm{mm}$ nodule in the left and right lung, respectively. There was a further metastatic $13 \times 7 \mathrm{~cm}^{2}$ mass in the liver and $10 \times 8 \mathrm{~cm}^{2}$ mass arising from the upper pole of the left kidney with convincing evidence of tumor thrombus in left renal vein. The patient was promptly referred under the care of the oncologist team and died within months.

Conclusion: The classical triad of loin pain, hematuria and abdominal mass for RCC is not that common and RCC should be suspected in patients complaining of upper GI pain with nonspecific symptoms. Furthermore, it is not necessary that patients complaining of "heartburn" have a GI cause, as pathology in other thoracic organs present in a similar manner.

Keywords: kidney cancer, renal cell carcinoma, gastrointestinal, metastasis

\section{Background}

The incidence of kidney cancer has increased by $78 \%$ in the UK over the last two decades. ${ }^{1}$ While the incidence of kidney cancer varies across countries, it is currently the 7th most common cancer in the UK, and 13th most common cancer worldwide. Kidney cancer is largely diagnosed in people over the age of 75 years, with the highest rates seen in $85-89$ age group for males and females. ${ }^{1}$ The condition often presents with nonspecific symptoms. The classical triad of loin pain, hematuria and abdominal mass is found only in $4 \%-17 \%$ of cases. ${ }^{2,3}$ The most common site for metastasis includes the lungs, liver, bone, adrenals and brain. ${ }^{4}$ There have also been reports of patients with renal cell carcinoma (RCC) presenting with upper gastrointestinal (GI) bleeds, due to invasion of the mass into the duodenum. Here, we report a case of a 49-year-old man with RCC with metastasis to the lungs and liver, presenting with pronounced GI symptoms without any indication of GI involvement.
Correspondence: Utkarsh Ojha Imperial College School of Medicine, Imperial College London, London SW7 2AZ, UK

Tel +447759667685

Email utkarsh.ojhal3@imperial.ac.uk 


\section{Case presentation}

A 49-year-old man with a history of heartburn presented to his general practitioner in January 2017. The heartburn had been getting worse since August 2016, but was now more intrusive and associated with nausea. He further described a reduction in appetite and had lost $3.2 \mathrm{~kg}$ in weight. He did not give any history of hematuria or loin pain to suspect a renal cause.

He had a past medical history of anxiety and depression for which he had been previously prescribed Citalopram and Mirtazapine. He underwent an endoscopy, which showed mild gastritis. He was therefore treated with omeprazole for a few months. He did not have any significant family history of cancer, though his father had colonic polyps. The patient was an ex-smoker with a 14 pack-year history and drank 15 UK unit drinks (8.45 standard drinks USA equivalent) weekly, for 7 years.

Clinical assessment, including abdominal examination was unremarkable and the patient was advised to commence omeprazole $20 \mathrm{mg}$ daily, and routine blood tests were arranged. All blood results were normal except for C-reactive protein which was $72.5 \mathrm{mg} / \mathrm{L}(0-3 \mathrm{mg} / \mathrm{L})$, serum (ALP) was slightly raised at $132 \mathrm{U} / \mathrm{L}(30-130 \mathrm{U} / \mathrm{L})$ and the erythrocyte sedimentation rate was $26 \mathrm{~mm} / \mathrm{h}(1-20 \mathrm{~mm} / \mathrm{h})$. Also the hemoglobin was at the lower end with a value of $130 \mathrm{~g} / \mathrm{L}(130-180 \mathrm{~g} / \mathrm{L})$.

The patient presented for a review 2 weeks later and complained there was a lack of relief in his symptoms despite taking the prescribed omeprazole. This time on examination his liver was found to be enlarged and tender. He was consequently referred urgently under the upper GI cancer pathway.

The GI specialists organized an esophagogastroduodenoscopy (OGD) and repeated the patient's blood tests. The OGD revealed that the patient had a hiatus hernia and gastritis. The GI team did not organize a CT scan on this occasion.

The patient was (campylobacter-like organism) negative. His C-reactive protein had risen to $105.4 \mathrm{mg} / \mathrm{L}(0-3 \mathrm{mg} / \mathrm{L})$; ALP had gone up to $168 \mathrm{U} / \mathrm{L}(30-130 \mathrm{U} / \mathrm{L})$ and erythrocyte sedimentation rate had rose to $29 \mathrm{~mm} / \mathrm{h}(1-20 \mathrm{~mm} / \mathrm{h})$. Following these results, the general practitioner arranged for an urgent $\mathrm{CT}$ scan, which suggested there was a metastatic $13 \times 7 \mathrm{~cm}^{2}$ mass in the liver (Figure 1) and $10 \times 8 \mathrm{~cm}^{2}$ mass arising from the upper pole of the left kidney (Figure 2) with convincing evidence of tumor thrombus in left renal vein, but not extending to the inferior vena cava. There were further 11 and $9 \mathrm{~mm}$ nodules in the left and right lung, respectively.

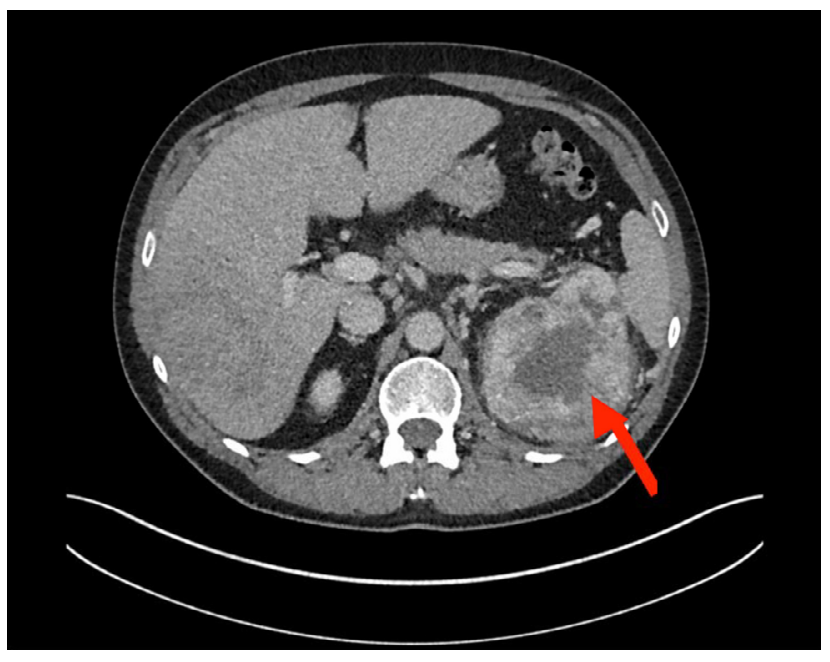

Figure I Abdomen-pelvis CT scan showing left renal mass encroaching the left renal vein.

Notes: Metastatic deposits in the liver are also present. The red arrow points to the carcinoma in the left kidney.

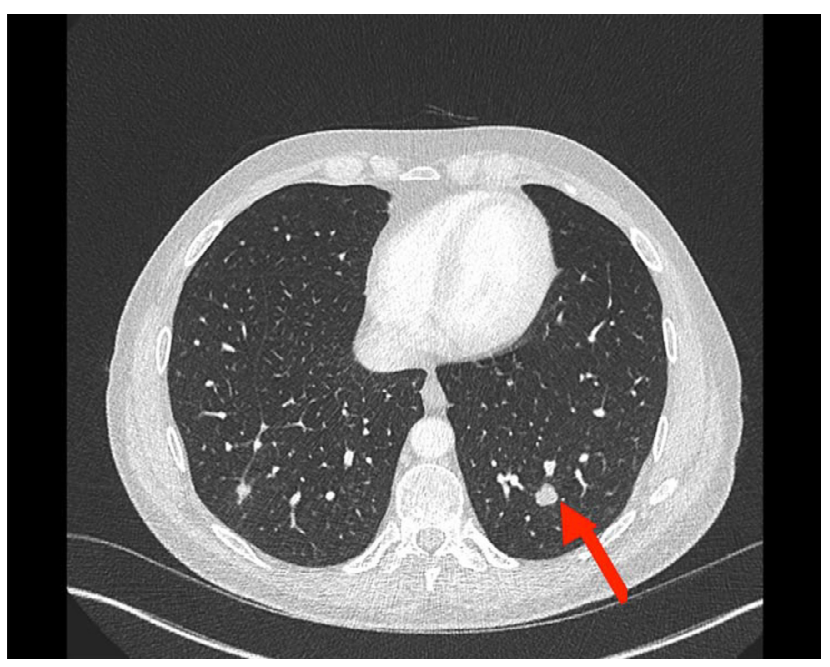

Figure 2 Abdomen-pelvis CT scan showing metastasis in left lung base.

Notes: The red arrow points to a mass in the left lung- which is the metastasis from the kidney.

The patient was subsequently referred under the care of the oncologist team and treated with Pazonanib, a receptor tyrosine kinase inhibitor. Initially, repeat CT scan showed shrinkage of the renal mass. However, the patient developed new secondary metastasis developing in the liver, and died in the following months.

\section{Discussion}

$\mathrm{RCC}$ arises from the renal epithelium and accounts for more than $90 \%$ of cancers in the kidney. ${ }^{5}$ The incidence of RCC varies by geography, with developed countries having a higher incidence. ${ }^{6}$ Occupational, environmental and genomic factors, such as smoking, hypertension and von Hippel-Lindau, are all thought to be implicated. ${ }^{6,7}$ 
In $25 \%-30 \%$ patients, $\mathrm{RCC}$ can metastasize to other organs. ${ }^{8}$ This spread can occur either through the lymphatic or haematogenous system or via direct invasion. Depending on the site of metastasis, patients may complain of varying symptoms. The classical triad of loin pain, hematuria and abdominal mass is relatively uncommon. There are many reports of metastasis from RCC into the GI tract. Mohamed et $\mathrm{al}^{9}$ described an 80-year-old patient with RCC who presented with melena and abdominal pain. An OGD showed a bleeding polypoidal mass within the second part of the duodenum. A further abdomen/pelvis CT scan revealed an $8 \mathrm{~cm}$ mass in the lower pole of the right kidney. In this case, the tumor had invaded the second part of the duodenum, which is anatomically anterior to the right kidney. Gorski et $\mathrm{al}^{10}$ reported an 80 -year-old male who presented to the emergency department with syncope and black stools. This patient was found to have low hemoglobin on admission. The patient had a history of RCC. A video capsule endoscopy demonstrated the source of the GI bleed in the proximal and distal jejunum and the proximal ileum. Histology showed a poorly differentiated malignant neoplasm, which was thought to be metastatic RCC. This case further highlights that RCC can spread to the small bowel. Tiwari et $\mathrm{a}^{11}$ described a 58-year-old female who presented to the emergency department with a history of melena and hematemesis. In this case, no lesions were found in the esophagus and duodenum. However, stomach histology showed vacuolated, clear cells. A further $\mathrm{CT}$ of the abdomen revealed a mass in the superior pole of the left kidney. Moreover, her chest X-ray showed pulmonary nodules suggesting RCC metastasis. VillarrealGarza et a $1^{12}$ reported that between 1987 and 2009, 4 out of 545 patients with RCC developed metastases to the stomach. Moreover, Pollheimer et a ${ }^{13}$ described that from a database of 2,082 patients with RCC, 5 developed metastases to the stomach. Sakurai et al ${ }^{14}$ conducted a review of the English literature in the PubMed database using the key words "renal cell carcinoma" and "gastric metastasis". The group identified 22 patients, of which 17 were men and 6 were women, whose mean age was 68.7 years (age range 53-83 years). In 19 cases, signs and symptoms included GI bleeding, melena, anemia and hematemesis.

"Heartburn" was the initial presenting complaint from our patient. Peptic ulcer was the initial differential; however, failure to respond to omeprazole and the OGD imaging did not confirm this. While the OGD showed hiatus hernia, the patient did not report any reduction in his symptoms after taking omeprazole. Furthermore, The CT scan did not show any involvement of the GI tract. The heartburn that the patient described could therefore have been pain in the patient's chest due to a respiratory cause ${ }^{15}$ as the scans revealed multiple metastases to both lungs. Furthermore, it must be acknowledged that our patient is much younger than those identified by Sakurai et al. ${ }^{14}$ Given his past medical history of depression and the nonspecific nature of his symptoms, including lack of signs of upper GI bleeding such as melena and hematemesis, there were no reasons to suggest a renal pathology in this case.

\section{Conclusion}

Our case highlights several key issues. First, this case adds further emphasis to the fact that the classical triad of loin pain, hematuria and a palpable abdominal mass in RCC is not that common, and in the absence of an identifiable cause, RCC should be considered as a potential differential for patients complaining of upper GI symptoms with red flag features such as weight loss and lethargy. Second, it is not necessary that patients complaining of "heartburn" have a GI cause, as pathology in other thoracic organs like lungs could present in a similar manner. It is likely that, in our case, the patient was complaining of heartburn due to lung metastases. Third, our patient suffered from depression; we recommend that doctors in primary care setting give extra attention and consider all possible causes for patients with mental health conditions presenting with nonspecific symptoms, as these individuals might be at increased risk having a sinister diagnosis missed. Finally, we advocate that family doctors in the UK should be able to refer patients directly for abdomen-pelvis CT imaging in cases where they suspect that GI symptoms may indicate either GI or kidney cancer. This will avoid delay in a definite diagnosis and management. These recommendations are based on a single case, further studies on a larger sample size are needed to evaluate whether a delay in organizing the appropriate imaging tests affect patients' mortality. Moreover, further studies must be conducted to assess the misdiagnosis rate in patients with mental health conditions.

\section{Data sharing statement}

Data generated or analyzed during this study are included in this published article, and the remaining data cannot be shared due to patient confidentiality.

Please note that the normal values of the lab results are provided in parenthesis.

\section{Ethics approval and consent to participate}

The patient provided written informed consent for the case details and any accompanying images to be published. 


\section{Acknowledgment}

DrVinod Ojha's current employment is at Mayfield Surgery, National Health Service, Stoke-on-Trent, ST3 4DW, UK.

\section{Author contributions}

All authors contributed to data analysis, drafting and revising the article, gave final approval of the version to be published, and agree to be accountable for all aspects of the work.

\section{Disclosure}

The authors report no conflicts of interest in this work.

\section{References}

1. Kidney cancer statistics [database on the Internet]. Oxford: Cancer Research UK; 2017. Available from: http://www.cancerresearchuk.org/ health-professional/cancer-statistics/statistics-by-cancer-type/kidneycancer. Accessed October 9, 2017.

2. Waters WB, Richie JP. Aggressive surgical approach to renal cell carcinoma: review of 130 cases. J Urol. 1979;122(3):306-308.

3. Griffiths LH, Thackray AC. Parenchymal carcinoma of the kidney. $\mathrm{Br}$ J Urol. 1949;21:128-151.

4. Zhao H, Han K, Li J, et al. A case of wedge resection of duodenum for massive gastrointestinal bleeding due to duodenal metastasis by renal cell carcinoma. World J SurgOncol. 2012;10:199.
5. Hsieh JJ, Purdue MP, Signoretti S, et al. Renal cell carcinoma. Nat Rev Dis Primers. 2017;3:17009.

6. Jonasch E, Gao J, Rathmell W. Renal cell carcinoma. BMJ. 2014;349:g4797.

7. Tidy C. Patient.co.uk - Doctor - Kidney cancer. Available from:http:// www.patient.co.uk/doctor/ renal-cancer. Accessed October 9, 2017.

8. Lam JS, Leppert JT, Belldegrun AS, Figlin RA. Novel approaches in the therapy of metastatic renal cell carcinoma. World J Urol. 2005;23(3):202-212.

9. Mohamed MO, Al-Rubaye S, Reilly IW, Mcgoldrick S. Renal cell carcinoma presenting as an upper gastrointestinal bleeding. BMJ Case Rep. 2015;2015:bcr2015211553.

10. Gorski RL, Jalil SA, Razick M, Jalil AA. An obscure cause of gastrointestinal bleeding: renal cell carcinoma metastasis to the small bowel. Int J Surg Case Rep. 2015;15:130-132.

11. Tiwari P, Tiwari A, Vijay M, Kumar S, Kundu AK. Upper gastrointestinal bleeding - Rare presentation of renal cell carcinoma. Urol Ann. 2010;2(3):127-129.

12. Villarreal-Garza C, Perez-Alvarez SI, Gonzalez-Espinoza IR, Leon-Rodriguez E. Unusual metastases in renal cell carcinoma: a single institution experience and review of literature. World J Oncol. 2010;1(4):149-157.

13. Pollheimer MJ, Hinterleitner TA, Pollheimer VS, Schlemmer A, Langner C. Renal cell carcinoma metastatic to the stomach: single-centre experience and literature review. BJU Int. 2008;102(3):315-319.

14. Sakurai K, Muguruma K, Yamazoe S, et al. Gastric metastasis from renal cell carcinoma with gastrointestinal bleeding: a case report and review of the literature. Int Surg. 2014;99(1):86-90.

15. Symptoms - Lung cancer - Cancer Research UK [database on the Internet]. Cancerresearchuk.org, 2018. Available from:http://www. cancerresearchuk.org/about-cancer/lung-cancer/symptoms. Accessed January 2, 2018.
International Medical Case Reports Journal

\section{Publish your work in this journal}

The International Medical Case Reports Journal is an international, peer-reviewed open-access journal publishing original case reports from all medical specialties. Previously unpublished medical posters are also accepted relating to any area of clinical or preclinical science. Submissions should not normally exceed 2,000 words or
4 published pages including figures, diagrams and references. The manuscript management system is completely online and includes a very quick and fair peer-review system, which is all easy to use. Visit http://www.dovepress.com/testimonials.php to read real quotes from published authors. 